Neurochemical Research

\title{
The effect of an NgR1 antagonist on the neuroprotection of cortical axons after cortical infarction in rats \\ --Manuscript Draft--
}

\begin{tabular}{|c|c|}
\hline Manuscript Number: & NERE2930R2 \\
\hline Full Title: & $\begin{array}{l}\text { The effect of an NgR1 antagonist on the neuroprotection of cortical axons after cortical } \\
\text { infarction in rats }\end{array}$ \\
\hline Article Type: & Original \\
\hline Keywords: & Nogo-66 receptor; Axon; Cortical infarction; regeneration; Signal pathway \\
\hline Corresponding Author: & $\begin{array}{l}\text { Xin Li } \\
\text { CHINA }\end{array}$ \\
\hline \multicolumn{2}{|l|}{$\begin{array}{l}\text { Corresponding Author Secondary } \\
\text { Information: }\end{array}$} \\
\hline \multicolumn{2}{|l|}{ Corresponding Author's Institution: } \\
\hline \multicolumn{2}{|l|}{$\begin{array}{l}\text { Corresponding Author's Secondary } \\
\text { Institution: }\end{array}$} \\
\hline First Author: & Hong Zhan \\
\hline \multicolumn{2}{|l|}{ First Author Secondary Information: } \\
\hline \multirow[t]{8}{*}{ Order of Authors: } & Hong Zhan \\
\hline & Shu-Jie Sun \\
\hline & Jie Cai \\
\hline & Ying-Qing Li \\
\hline & Chun-Lin Hu \\
\hline & Daniel H.S. Lee \\
\hline & Kwok-Fai So \\
\hline & Xin Li \\
\hline Order of Authors Secondary Information: & \\
\hline
\end{tabular}


The effect of an NgR1 antagonist on the neuroprotection of cortical axons after cortical infarction in rats

Running title: The neuroprotection of $\mathrm{NgR} 1$ antagonist on cortical axons

Hong Zhan ${ }^{1,6}$, Shu-Jie Sun ${ }^{4,6}$, Jie Cai ${ }^{1}$, Ying-Qing $\mathrm{Li}^{1}$, Chun-Lin Hu ${ }^{1}$, Daniel H.S. Lee ${ }^{3}$,

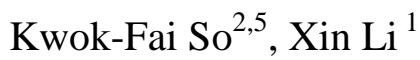

${ }^{1}$ Department of Emergency, The First Affiliated Hospital, Sun Yat-sen University, 58 ZhongShan II, Guangzhou, Guangdong, 510080, China

${ }^{2}$ Department of Anatomy and The State Key Laboratory of Brain and Cognitive sciences, The University of Hong Kong, 21 Sassoon Road, Pokfulam, Hong Kong SAR, China

${ }^{3}$ Roche R\&D Center (China) Ltd. 720 Cai Lun Road, Building, Pudong, Shanghai 201203, China

${ }^{4}$ Emergency Department, East Hospital of TongJi University, 150 Jimo Road, Shanghai, People's Republic of China

${ }^{5}$ GHM Institute of CNS Regeneration, Jinan University, Guangzhou, China

${ }^{6}$ These authors contributed equally to this work.

\section{Correspondence to:}

\section{Xin Li, MD}

Associate Professor

Department of Emergency

The First Affiliated Hospital

Sun Yat-sen University

58 ZhongShan Road II, Guangzhou, Guangdong, 510080, China

Telephone: $+86-20-28823350$

Fax: +86-20-28823350.

E-mail: xlidoct@qq.com 


\section{Abstract}

We investigated the effect of the soluble Nogo66 receptor $(\mathrm{sNgR}-\mathrm{Fc})$ on the protection of cortical axons after cortical infarction in rats. The cortical infarction was induced by photothrombotic cortical injury (PCI) in Sprague Dawley rats, after which sNgR-Fc was injected into the lateral ventricle. The ipsilesional cortices were harvested for analyses using histochemical and transmission-electron microscope techniques. The involved signaling pathways, which include RhoA, JNK, c-JUN and ATF-2, were detected by Western blot. Serious pathologies were found in the brains of the rats after injury, including edemas in the axoplasms of axons that have no medulla sheath and a thickening or shrinkage in the sheath of the axons that have medulla sheathes. However, these pathologies improved after sNgR-Fc treatment. The levels of GTP-RhoA, p-JNK, p-c-JUN and p-ATF-2 in the PCI group were increased when compared with their levels in the sham-operation group $(P<0.05)$, and animals receiving the $\mathrm{sNgR-Fc}$ treatment showed lower expression levels of these proteins when compared with the sham-operation group $(P<0.05)$. Our results suggest that $\mathrm{sNgR}-\mathrm{Fc}$ can alleviate the pathological changes of axons following cortical infarction via decreasing the activation of RhoA/JNK signaling pathways.

Key words: Nogo-66 receptor; Axon; Cortical infarction; Regeneration; Signal pathway 


\section{Introduction}

A brain infarction (also known as an ischemic stroke) is caused by the blockage of a cerebral artery by a blood clot, which results in the following effects: a critical reduction in blood flow, ischemia, anoxia, and, finally, ischemic necrosis or encephalomalacia in the brain. This condition is characterized clinically by high morbidity, high mortality, high disability rate, high recurrence rates, and it is difficult to treat. Because our population is aging, stroke is becoming a more serious threat and an urgent medical problem. Previous studies have shown that the central nerve system cannot regenerate after injury, as a result of factors that include the insufficiency of neural progenitor cells (NPCs) and a microenvironment that inhibits the regeneration of neurons [1]. Recent studies have demonstrated that the inhibition of axon regeneration after injuries to the central nervous system (CNS) were associated with several CNS myelin proteins, including Nogo-A, myelin-associated glycoprotein (MAG), and oligodendrocyte myelin glycoprotein (OMgp). These three proteins bind to the Nogo-66 receptor $(\mathrm{NgR} 1)$, which then leads to the downstream activation of RhoA (Ras homolog gene family, member A) via two transmembrane proteins, LINGO-1 and p75; these proteins inhibit the activity in neurons and their axons [2-4]. Jun N-terminal kinases (JNKs) are intracellular molecules related to stress stimuli. The activation of these molecules mediates many types of injury-induced apoptosis and plays a role in the regeneration of axons. However, the role of the JNK-signaling pathway in the presence of a brain infarction is still unclear. The administration of $\mathrm{sNgR}-\mathrm{Fc}$, a recombinant rat soluble $\mathrm{NgR}-\mathrm{Fc}$ fusion protein [5], has been found to block the interaction of myelin proteins with $\mathrm{NgR} 1$ effectively and to promote the regeneration of axons in rodent models of CNS injuries such as spinal cord injury [6-10]. A previous study has shown that anti-Nogo-A antibody promoted the behavioral outcome and 
corticospinal plasticity in a rat stroke model [11]. In this study, we established a stroke model in rats and observed the effects of $\mathrm{sNgR}-\mathrm{Fc}$ on the axonal pathology and the involved RhoA/JNK signaling pathways after cortical infarction.

\title{
Experimental Procedure
}

\author{
Animals \\ The animal experiments were approved by the Committee for the Use of Live Animals in \\ Teaching and Research at the Sun Yat-sen University. All of the experiments were performed \\ in a fully randomized and blinded fashion.
}

\section{Photothrombotic cortical injury}

Photothrombotic ischemia was induced in the rat parietal cortex using previously described methods $[9,11,12]$ with the modifications as outlined below. Twenty seven male SD rats weighing $250 \mathrm{~g}$ were anesthetized by an intraperitoneal injection of ketamine $(80 \mathrm{mg} / \mathrm{kg})$ and xylazine $(8 \mathrm{mg} / \mathrm{kg})$. Dilute Rose-Bengal in saline $(40 \mathrm{mg} / \mathrm{kg}$ body weight) was infused into the femoral vein. The portion of the skull exposed at $3 \mathrm{~mm}$ posteriorly to the bregma and 3 $\mathrm{mm}$ laterally from the midline was illuminated with a cold, white light beam (Volpi Intralux 6000, $150 \mathrm{~W}$; Volpi AG, Schlieven, Switzerland) for $8 \mathrm{~min}$ at maximum output via a fiber-optic bundle with a $10 \mathrm{~mm}$ aperture. The animals were randomly grouped into sham-operation (operation + Rose-Bengal), PBS (operation + Rose-Bengal + PBS), or sNgR-Fc (operation + Rose-Bengal $+\mathrm{sNgR}-\mathrm{Fc}$ ) groups ( $n=9$ for each group). A solution of sNgR-Fc (400 $\mu \mathrm{g} / \mathrm{kg}$ body weight) in $10 \mu \mathrm{l}$ PBS or equivalent PBS was only once injected into the ipsilateral ventricle using a 26 -gauge sterile microsyringe $24 \mathrm{~h}$ after photothrombotic cortical injury [11]. The site of injection was at $1 \mathrm{~mm}$ posteriorly to the bregma and $1.5 \mathrm{~mm}$ 
laterally from the midline, and the depth of injection was about 3.5 4.0 mm. For each group, the whole cerebrum of 3 animals was collected $24 \mathrm{~h}$ after injury for tissue staining. The ipsilateral cortex of peripheral penumbra at $7 \mathrm{~mm}$ posteriorly to the bregma and $3 \mathrm{~mm}$ laterally from the midline of rats was collected at $27 \mathrm{~d}$ after injury for electron microscopy examination ( $n=3$ for each group) and for Western blotting ( $n=3$ for each group).

\section{Triphenyltetrazolium chloride staining}

To evaluate the extent of cortical infarction, we used 2, 3, 5-Triphenyltetrazolium chloride (TTC) to assess cerebral injury. At $24 \mathrm{~h}$ after PCI, the animals were sacrificed using an overdose of pentobarbital sodium (150 mg/kg, Alcon-Couvreur, Rijksweg, Puurs, Belgium). The brains were removed immediately and then were chilled at $-30{ }^{\circ} \mathrm{C}$ for 4 min to slightly freeze the tissue. Two-mm coronal sections from the olfactory bulb to the cerebellum were prepared, stained with $1.5 \%$ TTC (Genetime) at $37{ }^{\circ} \mathrm{C}$ for $30 \mathrm{~min}$, and fixed in $10 \%$ buffered formalin solution.

\section{Transmission electron microscopy}

Seven days after PCI, the peripheral penumbra at $7 \mathrm{~mm}$ posteriorly to the bregma and $3 \mathrm{~mm}$ laterally from the midline on the injury side was removed and immediately cut into $0.5 \mathrm{~cm}^{3}$ cubes at $0{ }^{\circ} \mathrm{C}$, fixed with $4 \%$ paraformaldehyde for $4 \mathrm{~h}$, and washed with PBS. Then, the tissue was fixed with $2 \%$ osmic acid for $2 \mathrm{~h}$, washed with pure water, dehydrated with a mixture of ethanol, propylene oxide, and resin, embedded in pure resin, and ultramicrocut and stained with uranyl acetate and lead citrate $[13,14]$. The sections were observed under an HE-800 transmission electron microscope (Hitachi, Japan).

\section{Western blotting}


The cortex from the injury side was collected at 7 days after injury and homogenized in a $1 \%$ phosphatase inhibitor), and incubated on ice for $30 \mathrm{~min}$. The protein lysate was then centrifuged at 13,500 rpm for $30 \min$ at $4{ }^{\circ} \mathrm{C}$. The supernatant was aliquoted and stored at $-80{ }^{\circ} \mathrm{C}$ until its use. The supernatant was measured for its protein concentration using a Bio-Rad DC Protein Assay Kit (Bio-Rad Laboratories, CA, USA). A $40 \mu \mathrm{g}$ aliquot of protein from each sample was subjected to 5-12\% SDS-polyacrylamide gel electrophoresis and transferred onto a PVDF membrane. Each membrane was blocked with 5\% non-fat milk and $2 \%$ bovine serum albumin in Tris-buffered saline containing $0.1 \%$ Tween 20 (TBST) for $1 \mathrm{~h}$ at room temperature and then probed with rabbit anti-p-JNK (Cell Signaling Technology, MA, USA), anti-p-c-JUN (Cell Signaling Technology), p-ATF-2 (Cell Signaling Technology), total-JNK (Cell Signaling Technology) and total-RhoA antibodies at $4{ }^{\circ} \mathrm{C}$ overnight. As a gel loading control, $\beta$-actin was used. After washing, the membranes were incubated for $2 \mathrm{~h}$ with horseradish peroxidase-conjugated goat anti-rabbit antibody (1:2000; DakoCytomation, Denmark). Its immunoreactivity was visualized using the Amersham enhanced chemiluminescence kit (Amersham, Piscataway, NJ, USA). The protein loading was controlled using the goat antibody against $\beta$-actin (C-11; Santa Cruz Biotechnology). The quantification of the results was performed by densitometry, and the results were analyzed as total integrated densitometric values (arbitrary units). The protein GTP-RhoA was pulled down using a RhoA activation assay kit, according to the manufacturer's instruction (Cytoskeleton, Denver, CO, USA) and assayed by Western blotting using an antibody against RhoA (Cytoskeleton). All experiments for Western blotting were performed with 3 animals in each group, and the samples were run on the gels as individual animals. 


\section{Data and statistical analysis}

The values are presented as the mean $\pm \mathrm{SD}$. The statistical analyses was performed using Student's t-test for comparisons between two groups or the one-way analysis of variance (ANOVA) followed by post-hoc tests (Student-Neuman-Keuls) for comparisons of more than two groups. The data were analyzed statistically with the software SPSS 12.0. The significance level was set at $\mathrm{P}<0.05$.

\section{Results}

\section{Measurement of brain infarct volume and identification of blood brain barrier integrity}

After TTC staining, the rats in the sham group did not appear to have any infarctions (Fig. 1b). However, the right parietal lobes of the rats $24 \mathrm{~h}$ after PCI presented pale infarctions that were bowl-shaped, with the bottom pointing to the lateral ventricle; these infarctions affected the entire cortex. The total infarct volumes were $297.1 \pm 23.4 \mu 1$ in the PBS group and $285.4 \pm 19.7 \mu 1$ for the $\mathrm{sNgR}-\mathrm{Fc}$ group respectively before the treatment. The locations of the infarctions were stable, and the infarctions showed similar volumes to those in the rats (Fig. 1).

\section{Pathological changes of axons}

The morphology of ischemic penumbra on the injury side was evaluated using TEM at 7 days after PCI. Compared with the normal axons observed in the sham group (Fig. 2a), more serious pathologies were observed in the PCI group (Fig. 2b). For the axons without a medulla sheath, many edemas, dilutions of cytoplasmic matrices, and axonal fusions or dissolutions were found. Occasionally, we observed that oligodendrocytes appeared to "swallow" the axons (Fig. 2b). For axons with a medulla sheath, compared with the sham 
group, thickening or shrinking was more in the axoplasm of the fibers, and amyloidosis and separated from the inner layers of the myelin (Fig. 2e). In addition, there were only minor pathological changes, including slight nuclear edemas with complete nucleoli, slightly swollen mitochondria, and slightly widened endoplasmic reticula with complete ribosomes and Golgi bodies. In unmyelinated axons, there were some axonal edemas, axonal deformities, and dilutions of cytoplasmic matrices; in addition, there were no axonal fusions or cytophagic effects of oligodendrocytes (Fig. 2c). In myelinated axons, the morphology of axons was almost normal. There was little demyelination and no amyloidosis of the myelin sheath was found (Fig. 2f). Compared with normal synapses (Fig. 2g), the synaptic cleft widened, and there was edema in the PBS group (Fig. 2h). However, no clear edema or widening of the synaptic cleft was observed in the group that received the sNgR-Fc treatment (Fig. 2i).

\section{sNgR-Fc inhibited RhoA signal pathway}

The level of GTP-RhoA in the PBS group was significantly higher than that in the sham-operation group $(P<0.05)$. After treatment with $\mathrm{sNgR}-\mathrm{Fc}$, the level of GTP-RhoA was significantly decreased. Moreover, the level of Total-RhoA was not different among the three groups (Fig.3, Table 1). These data indicate that sNgR-Fc could decrease the activation of RhoA.

\section{sNgR-Fc inhibit the activation of SAPK/JNK signal pathway}

The levels of p-JNK1, 2 and its downstream targets, p-c-JUN and p-ATF-2, in the cortex around the infarcts in the PCI group were significantly higher compared with those in the sham operation group $(P<0.05)$. In contrast, the cortex in the $\mathrm{sNgR}-\mathrm{Fc}$-treated group showed, 
on average, reductions in the levels of p-JNK1, 2, p-c-JUN and p-ATF-2 to their basal levels $(P<0.05)$. The levels of total JNK1, 2 were not different among the three groups $(P>0.05)$. These results demonstrate that the cortical infarction injury activates the SAPK/JNK signal pathway and that treatment with $\mathrm{sNgR}-\mathrm{Fc}$ has the potential to decrease or prevent this activation (Fig.3, Table 1).

\section{Discussion}

Watson et al reported a stroke model induced by a photochemical method in 1985 [12]. The principle underlying this model was based on a photochemical reaction. Following the injection of a potent photosensitive agent into rats, ischemic lesions were formed by irradiating the left parietal convexities of the exposed skulls under a light with a specific wavelength. Free radicals were released, damaging the endothelium of the cerebral vessels and inducing platelet aggregation. Furthermore, this pathology causes thrombosis in cerebral parenchymal vessels and results in irreversible hypoxic-ischemic brain damage (HIBD). Because of the advantages of a stable location and infarction volume, a low mortality rate, and a good replication rate, the stroke model is widely used in current studies of brain injury. In this study, we successfully induced a cortical ischemic infarction model in rats in which the BBB was also damaged. The primary pathological features of stroke were induced, and the volumes of infarction were consistent. No infarction and no burn were observed in the sham-group, indicating that the light stimulation alone did not induce the infarction and that it acts as a good control.

Delayed neuron death (DND) is an important pathology of cerebral ischemia and cerebral degenerative disease. Cell apoptosis was the primary DND pattern after an acute 
HIBD, which aggravated the injury of sub-acute or chronic cerebral infarction $[15,16]$. In our edemas in the axoplasm of axons that have no medulla sheath, and thickening or shrinkage in the sheaths of the axons that have a medulla sheath. However, these conditions improved after $\mathrm{sNgR}-\mathrm{Fc}$ treatment. The administration of the soluble $\mathrm{NgR} 1$ fusion protein $(\mathrm{sNgR}-\mathrm{Fc})$ effectively blocked the interaction of myelin molecules with $\mathrm{NgR} 1$ and promoted axon sprouting and functional recovery after spinal cord injuries[7-9], or dorsal root rhizotomy[10]. A previous study found that Nogo-A is involved in the secondary axonal degeneration of the thalamus with cerebral infarction in hypertensive rats [17] and after a focal ischemic stroke [18]. Anti-Nogo-A antibody improved behavioral outcome and corticospinal plasticity but did not decrease the infarct volume after experimental stroke [11]. In this study, $\mathrm{sNgR}-\mathrm{Fc}$ did not cause any difference on infarct volume, but still provided protection of axons as observed in TEM.

Nogo-A, MAG and OMgp were considered to be the inhibitory factors of axonal regeneration in the CNS. NgR1 mediates their inhibitory effect via two co-receptors, $\mathrm{p} 75$ and Lingo-1, and transduces the signals via RhoA and its downstream pathways $[19,20]$. In this study, the level of the GTP-RhoA protein in the model group was significantly higher than that of the sham-operation group. With the treatment of sNgR-Fc, the level of the GTP-RhoA protein was significantly decreased, suggesting that $\mathrm{sNgR}-\mathrm{Fc}$ may promote axonal recovery by preventing the activation of RhoA after cerebral infarction.

The stress-activated protein kinase/c-Jun N-terminal kinase (SAPK/JNK) signaling pathway is a powerful signaling pathway under the stresses of ultraviolet light, radiation and inflammation [21-23]. In publications on neuronal apoptosis, some of the proteins in the 
mitogen-activated protein kinases (MAPK) signaling pathways have been well-studied in include three members: the extracellular signal-regulated protein kinases (ERK), JNK and p38 [24]. The JNK/SAPK and p38 are induced by cellular stress and some of the cytokines. The JNK protein can be activated by many stress stimulators, such as lipopolysaccharide (LPS), tumor necrosis factor- $\alpha$ (TNF- $\alpha$ ), interleukin (IL)-1 or ultraviolet light. Activation of the JNK signaling pathway is related to cell apoptosis [24]. Following its activation, JNKs may phosphorylate specific sites of some of the transcription factors, such as ATF-2, SAP-1 and Elk-1, and increase the expression of genes, subsequently increasing the synthesis of proteins that may participate in the apoptosis pathway and cause cell death [25]. We found high levels of p-JNK, p-c-JUN and p-ATF-2 after stroke injury, indicating that cortical infarction activates the SAPK/JNK signal pathway and leads to the pathology of tissues and cells. The administration of sNgR-Fc decreased the activation of those proteins, suggesting that $\mathrm{sNgR}-\mathrm{Fc}$ has the potential to prevent or decrease the activation of the SAPK/JNK signal pathway. We previously identified that sNgR-Fc binds to Nogo66, OMgp, and MAG [9] and inhibited the Nogo66-NgR interaction [6]. sNgR-Fc may protect axons by inhibiting the interaction of Nogo-A-NgR1 after stroke injury, decreasing the activation of RhoA and JNK. A schematic diagram illustrating the proposed mechanism for $\mathrm{sNgR}-\mathrm{Fc}$ on axons in stroke is shown in Figure 4: In normal conditions, the cortex expresses low levels of Nogo-A and NgR1. However, cortical infarction under stroke injury increases the expression of Nogo-A and NgR1. Nogo-A activates RhoA and JNK signaling pathways via interacting with NgR1 and then results in pathological changes on axons. $\mathrm{sNgR}-\mathrm{Fc}$ perturbs the interaction of Nogo-A and NgR1, decreases the activation of RhoA and JNK signaling pathways and 
relieving the pathological changes of axons.

RhoA regulates the intracellular microfilament associated with cell proliferation through a series of complex mechanisms [26]. Previous studies have observed that RhoA stimulates Jun expression through the Rho-associated kinase (ROCK), which phosphorylates c-Jun and ATF2 after binding to the c-Jun promoter [27]. In this study, we observed that changes in the expression of p-JNK, p-c-Jun and p-ATF-2 were consistent with changes in the GTP-RhoA level following both the cerebral infarction and the $\mathrm{sNgR}-\mathrm{Fc}$ treatment. These findings suggest that sNgR-Fc can relieve the axonal pathology partially by decreasing the activation of the SAPK/JNK signal pathways.

In summary, pathological changes in axons were induced by the cerebral hypoxia-ischemia for an extended period after the cortical infarction. This phenomenon may be associated with the activation of RhoA/ROCK/JNK/c-Jun signaling pathways. We determined that an $\mathrm{NgR} 1$ antagonist, $\mathrm{SNgR}-\mathrm{Fc}$, alleviated axonal pathology changes and prevented the activation of RhoA/ROCK/JNK/c-Jun signaling pathways. Further studies should be performed before this treatment is used in a clinical study.

\section{Acknowledgements}

This study was supported by funding from the NSFC (81272062, 81071030), Science and Technology Foundation of Guangdong Province, China (2012B031800286 , 2010B031600089) and the Fundamental Research Funds for the Central Universities (09ykpy31). The funders had no role in the study design, data collection, analysis, decision to publish or the preparation of the manuscript. Biogen Idec, Inc. provided the sNgR-Fc in the study. 


\section{Disclosure of potential conflicts of interest}

1

2

3

4

5

6

7

8

9

10

11

12

13

14

15

16

17

18

19

20

21

22

23

24

25

26

27

28

29

30

31

32

33

34

35

36

37

38

39

40

41

42

43

44

45

46

47

48

49

50

51

52

53

54

55

56

57

58

59

60

61

62

63

64

65

The authors indicate no potential conflicts of interest. 


\section{References}

1. Bühnemann C, Scholz A, Bernreuther C, Malik CY, Braun H, Schachner M et al (2006)

Neuronal differentiation of transplanted embryonic stem cell-derived precursors in stroke lesions of adult rats. Brain 129:3238-3248

2. Chen MS, Huber AB, van der Haar ME, Frank M, Schnell L, Spillmann AA et al (2000) Nogo-A is a myelin-associated neurite outgrowth inhibitor and an antigen for monoclonal antibody IN-1. Nature 403:434-439

3. Domeniconi M, Cao Z, Spencer T, Sivasankaran R, Wang K, Nikulina E et al (2002) Myelin-associated glycoprotein interacts with the Nogo66 receptor to inhibit neurite outgrowth. Neuron 35:283-290

4. Wang KC, Koprivica V, Kim JA, Sivasankaran R, Guo Y, Neve RL et al (2002) Oligodendrocyte-myelin glycoprotein is a Nogo receptor ligand that inhibits neurite outgrowth. Nature 417:941-944

5. GrandPre T, Li S, Strittmatter SM (2002) Nogo-66 receptor antagonist peptide promotes axonal regeneration. Nature 417:547-551

6. Harvey PA, Lee DH, Qian F, Weinreb PH, Frank E (2009) Blockade of Nogo receptor ligands promotes functional regeneration of sensory axons after dorsal root crush. $\mathrm{J}$ Neurosci 29:6285-6295

7. Ji B, Li M, Budel S, Pepinsky RB, Walus L, Engber TM et al (2005) Effect of combined treatment with methylprednisolone and soluble Nogo-66 receptor after rat spinal cord injury. Eur J Neurosci 22:587-594

8. Lee JK, Kim JE, Sivula M, Strittmatter SM (2004) Nogo receptor antagonism promotes stroke recovery by enhancing axonal plasticity. J Neurosci 24:6209-6217 
9. Li S, Liu BP, Budel S, Li M, Ji B, Walus L et al (2004) Blockade of Nogo-66, myelin-associated glycoprotein, and oligodendrocyte myelin glycoprotein by soluble Nogo-66 receptor promotes axonal sprouting and recovery after spinal injury. J Neurosci 24:10511-10520

10. MacDermid VE, McPhail LT, Tsang B, Rosenthal A, Davies A, Ramer MS (2004) A soluble Nogo receptor differentially affects plasticity of spinally projecting axons. Eur J Neurosci 20:2567-2579

11. Wiessner C, Bareyre FM, Allegrini PR, Mir AK, Frentzel S, Zurini M, et al (2003) Anti-Nogo-A antibody infusion 24 hours after experimental stroke improved behavioral outcome and corticospinal plasticity in normotensive and spontaneously hypertensive rats. J Cereb Blood Flow Metab. 23:154-65.

12. Watson BD, Dietrich WD, Busto R, Wachtel MS, Ginsberg MD (1985) Induction of reproducible brain infarction by photochemically initiated thrombosis. Ann Neurol $17: 497-504$

13. Gao M, Zhu SY, Tan CB, Xu B, Zhang WC, Du GH (2010) Pinocembrin protects the neurovascular unit by reducing inflammation and extracellular proteolysis in MCAO rats. J Asian Nat Prod Res 12:407-418

14. Zheng YQ, Liu JX, Wang JN, Xu L (2007) Effects of crocin on reperfusion-induced oxidative/nitrative injury to cerebral microvessels after global cerebral ischemia. Brain Res 1138:86-94

15. Culmsee C, Plesnila N (2006) Targeting Bid to prevent programmed cell death in neurons. Biochem Soc Trans 34:1334-1340

16. Plesnila N, Zhu C, Culmsee C, Gröger M, Moskowitz MA, Blomgren K (2004) Nuclear 
translocation of apoptosis-inducing factor after focal cerebral ischemia. J Cereb Blood Flow Metab 24:458-466

17. Wang F, Liang Z, Hou Q, Xing S, Ling L, He M et al (2007) Nogo-A is involved in secondary axonal degeneration of thalamus in hypertensive rats with focal cortical infarction. Neurosci Lett 417:255-260

18. Cheatwood JL, Emerick AJ, Schwab ME, Kartje GL (2008) Nogo-A expression after focal ischemic stroke in the adult rat. Stroke 39:2091-2098

19. Kubo T, Hata K, Yamaguchi A, Yamashita T (2007) Rho-ROCK inhibitors as emerging strategies to promote nerve regeneration. Curr Pharm Des 13:2493-2499

20. Kubo T, Yamashita T (2007) Rho-ROCK inhibitors for the treatment of CNS injury. Recent Patents CNS Drug Discov 2:173-179

21. Schwab TS, Madison BB, Grauman AR, Feldman EL (2005) Insulin-like growth factor-I induces the phosphorylation and nuclear exclusion of forkhead transcription factors in human neuroblastoma cells. Apoptosis 10:831-840

22. Zhang HM, Yuan J, Cheung P, Luo H, Yanagawa B, Chau D et al (2003) Overexpression of interferon-gamma-inducible GTPase inhibits coxsackievirus B3-induced apoptosis through the activation of the phosphatidylinositol 3-kinase/Akt pathway and inhibition of viral replication. J Biol Chem 278:33011-33019

23. Koh SH, Lee YB, Kim KS, Kim HJ, Kim M, Lee YJ et al (2005) Role of GSK-3beta activity in motor neuronal cell death induced by G93A or A4V mutant hSOD1 gene. Eur J Neurosci 22:301-309

24. Yasuda S, Sugiura H, Tanaka H, Takigami S, Yamagata K (2011) p38 MAP kinase inhibitors as potential therapeutic drugs for neural diseases. Cent Nerv Syst Agents Med 
Chem. 11:45-59.

25. Humar M, Loop T, Schmidt R, Hoetzel A, Roesslein M, Andriopoulos N et al (2007) The mitogen-activated protein kinase p38 regulates activator protein 1 by direct phosphorylation of c-Jun. Int J Biochem Cell Biol 39:2278-2288

26. Marinissen MJ, Chiariello M, Tanos T, Bernard O, Narumiya S, Gutkind JS (2004) The small GTP-binding protein RhoA regulates c-jun by a ROCK-JNK signaling axis. Mol Cell 14:29-41

27. Karin M, Liu Z, Zandi E (1997) AP-1 function and regulation. Curr Opin Cell Biol $9: 240-246$ 


\section{Figure Legends}

Figure 1. The morphology and characteristics of the rat brain after a stroke induced by photothrombotic cortical injury. (a) Representative photographs of the coronal brain sections stained with 2,3,5-triphenyltetrazolium chloride in rats, (b) sham-operated rats, (c) and photothrombotic cortical injury (PCI) rats. White indicates the infarct area (arrow).

\section{Figure 2. The protective effect of SNgR-Fc on axon neurons under transmission electron} microscope after stroke injury. Ultrastructural appearances of morphology of axons in sham-operated, PBS and sNgR-Fc groups: (a) Normal unmyelinated axons in sham-operated group; (b) Extensive edema, axon deformity, dilution of cytoplasmic matrices and axonal fusion in stroke model; (c) Slight edema and dilution of cytoplasmic matrices with the treatment of sNgR-Fc in stroke model; (d) Normal myelinated axons in sham-operated group; (e) Thickening, shrinking or amyloidosis was more in stroke model; (f) Little demyelination and no amyloidosis of the myelin sheath were found with the treatment of $\mathrm{sNgR}-\mathrm{Fc}$ in stroke model; (g) Normal synapses in the sham-operated group; (h) Widened and swollen synaptic cleft in stroke model; (i) Approximately normal synapses with the treatment of $\mathrm{sNgR}-\mathrm{Fc}$ in stroke model. Arrows show the changes in axons.

Figure 3. The RhoA, SAPK/JNK signaling pathways after stroke injury and with the treatment of sNgR-Fc under Western blotting. The levels of p-JNK, p-c-JUN, p-ATF-2 and GTP-RhoA increased after stroke injury. Treatment with sNgR-Fc decreased the levels of p-JNK, p-c-JUN, p-ATF-2 and GTP-RhoA to normal levels.

Figure 4. The diagram of the signaling pathways involved in the sNgR-Fc on axons after stroke injury. In the normal condition, there is low level of Nogo-A and NgR1 in the cortex. However, the expression of Nogo-A and NgR1 is increased under stroke injury. The increased Nogo-A binds with NgR1 to activate the downstream pathways of RhoA and JNK, and then results in axonal pathology. The treatment of $\mathrm{sNgR}-\mathrm{Fc}$ inhibits the interaction of Nogo-A and $\mathrm{NgR} 1$, decreases the activation of RhoA and JNK signaling pathways and then relieves axonal pathology. 
The effect of an NgR1 antagonist on the neuroprotection of cortical axons after cortical infarction in rats

Running title: The neuroprotection of $\mathrm{NgR} 1$ antagonist on cortical axons

Hong Zhan ${ }^{1,6}$, Shu-Jie Sun ${ }^{4,6}$, Jie Cai ${ }^{1}$, Ying-Qing $\mathrm{Li}^{1}$, Chun-Lin Hu ${ }^{1}$, Daniel H.S. Lee ${ }^{3}$,

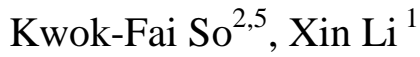

${ }^{1}$ Department of Emergency, The First Affiliated Hospital, Sun Yat-sen University, 58 ZhongShan II, Guangzhou, Guangdong, 510080, China

${ }^{2}$ Department of Anatomy and The State Key Laboratory of Brain and Cognitive sciences, The University of Hong Kong, 21 Sassoon Road, Pokfulam, Hong Kong SAR, China

${ }^{3}$ Roche R\&D Center (China) Ltd. 720 Cai Lun Road, Building, Pudong, Shanghai 201203, China

${ }^{4}$ Emergency Department, East Hospital of TongJi University, 150 Jimo Road, Shanghai, People's Republic of China

${ }^{5}$ GHM Institute of CNS Regeneration, Jinan University, Guangzhou, China

${ }^{6}$ These authors contributed equally to this work.

\section{Correspondence to:}

\section{Xin Li, MD}

Associate Professor

Department of Emergency

The First Affiliated Hospital

Sun Yat-sen University

58 ZhongShan Road II, Guangzhou, Guangdong, 510080, China

Telephone: $+86-20-28823350$

Fax: +86-20-28823350.

E-mail: xlidoct@qq.com 


\begin{abstract}
We investigated the effect of the soluble Nogo66 receptor $(\mathrm{sNgR}-\mathrm{Fc})$ on the protection of cortical axons after cortical infarction in rats. The cortical infarction was induced by photothrombotic cortical injury (PCI) in Sprague Dawley rats, after which sNgR-Fc was injected into the lateral ventricle. The ipsilesional cortices were harvested for analyses using histochemical and transmission-electron microscope techniques. The involved signaling pathways, which include RhoA, JNK, c-JUN and ATF-2, were detected by Western blot. Serious pathologies were found in the brains of the rats after injury, including edemas in the axoplasms of axons that have no medulla sheath and a thickening or shrinkage in the sheath of the axons that have medulla sheathes. However, these pathologies improved after sNgR-Fc treatment. The levels of GTP-RhoA, p-JNK, p-c-JUN and p-ATF-2 in the PCI group were increased when compared with their levels in the sham-operation group $(P<0.05)$, and animals receiving the $\mathrm{sNgR}-\mathrm{Fc}$ treatment showed lower expression levels of these proteins when compared with the sham-operation group $(P<0.05)$. Our results suggest that $\mathrm{sNgR}-\mathrm{Fc}$ can alleviate the pathological changes of axons following cortical infarction via decreasing the activation of RhoA/JNK signaling pathways.
\end{abstract}

Key words: Nogo-66 receptor; Axon; Cortical infarction; Regeneration; Signal pathway 


\section{Introduction}

A brain infarction (also known as an ischemic stroke) is caused by the blockage of a cerebral artery by a blood clot, which results in the following effects: a critical reduction in blood flow, ischemia, anoxia, and, finally, ischemic necrosis or encephalomalacia in the brain. This condition is characterized clinically by high morbidity, high mortality, high disability rate, high recurrence rates, and it is difficult to treat. Because our population is aging, stroke is becoming a more serious threat and an urgent medical problem. Previous studies have shown that the central nerve system cannot regenerate after injury, as a result of factors that include the insufficiency of neural progenitor cells (NPCs) and a microenvironment that inhibits the regeneration of neurons [1]. Recent studies have demonstrated that the inhibition of axon regeneration after injuries to the central nervous system (CNS) were associated with several CNS myelin proteins, including Nogo-A, myelin-associated glycoprotein (MAG), and oligodendrocyte myelin glycoprotein (OMgp). These three proteins bind to the Nogo-66 receptor $(\mathrm{NgR} 1)$, which then leads to the downstream activation of RhoA (Ras homolog gene family, member A) via two transmembrane proteins, LINGO-1 and p75; these proteins inhibit the activity in neurons and their axons [2-4]. Jun N-terminal kinases (JNKs) are intracellular molecules related to stress stimuli. The activation of these molecules mediates many types of injury-induced apoptosis and plays a role in the regeneration of axons. However, the role of the JNK-signaling pathway in the presence of a brain infarction is still unclear. The administration of sNgR-Fc, a recombinant rat soluble NgR-Fc fusion protein [5], has been found to block the interaction of myelin proteins with $\mathrm{NgR} 1$ effectively and to promote the regeneration of axons in rodent models of CNS injuries such as spinal cord injury [6-10]. A previous study has shown that anti-Nogo-A antibody promoted the behavioral outcome and corticospinal plasticity in a rat stroke model [11]. In this study, we established a stroke model 
in rats and observed the effects of $\mathrm{sNgR}-\mathrm{Fc}$ on the axonal pathology and the involved RhoA/JNK signaling pathways after cortical infarction.

\title{
Experimental Procedure
}

\begin{abstract}
Animals
The animal experiments were approved by the Committee for the Use of Live Animals in Teaching and Research at the Sun Yat-sen University. All of the experiments were performed in a fully randomized and blinded fashion.
\end{abstract}

\section{Photothrombotic cortical injury}

Photothrombotic ischemia was induced in the rat parietal cortex using previously described methods $[9,11,12]$ with the modifications as outlined below. Twenty seven male SD rats weighing $250 \mathrm{~g}$ were anesthetized by an intraperitoneal injection of ketamine $(80 \mathrm{mg} / \mathrm{kg})$ and xylazine $(8 \mathrm{mg} / \mathrm{kg})$. Dilute Rose-Bengal in saline $(40 \mathrm{mg} / \mathrm{kg}$ body weight) was infused into the femoral vein. The portion of the skull exposed at $3 \mathrm{~mm}$ posteriorly to the bregma and 3 $\mathrm{mm}$ laterally from the midline was illuminated with a cold, white light beam (Volpi Intralux 6000, $150 \mathrm{~W}$; Volpi AG, Schlieven, Switzerland) for $8 \mathrm{~min}$ at maximum output via a fiber-optic bundle with a $10 \mathrm{~mm}$ aperture. The animals were randomly grouped into sham-operation (operation + Rose-Bengal), PBS (operation + Rose-Bengal + PBS), or $\mathrm{sNgR}-\mathrm{Fc}$ (operation + Rose-Bengal $+\mathrm{sNgR}-\mathrm{Fc}$ ) groups ( $n=9$ for each group). A solution of sNgR-Fc (400 $\mu \mathrm{g} / \mathrm{kg}$ body weight) in $10 \mu \mathrm{l}$ PBS or equivalent PBS was only once injected into the ipsilateral ventricle using a 26-gauge sterile microsyringe $24 \mathrm{~h}$ after photothrombotic cortical injury [11]. The site of injection was at $1 \mathrm{~mm}$ posteriorly to the bregma and $1.5 \mathrm{~mm}$ laterally from the midline, and the depth of injection was about $3.5 \sim 4.0 \mathrm{~mm}$. For each group, the whole cerebrum of 3 animals was collected $24 \mathrm{~h}$ after injury for tissue staining. The 
ipsilateral cortex of peripheral penumbra at $7 \mathrm{~mm}$ posteriorly to the bregma and $3 \mathrm{~mm}$ laterally from the midline of rats was collected at $27 \mathrm{~d}$ after injury for electron microscopy examination ( $n=3$ for each group) and for Western blotting ( $n=3$ for each group).

\section{Triphenyltetrazolium chloride staining}

To evaluate the extent of cortical infarction, we used 2, 3, 5-Triphenyltetrazolium chloride (TTC) to assess cerebral injury. At $24 \mathrm{~h}$ after PCI, the animals were sacrificed using an overdose of pentobarbital sodium (150 mg/kg, Alcon-Couvreur, Rijksweg, Puurs, Belgium). The brains were removed immediately and then were chilled at $-30{ }^{\circ} \mathrm{C}$ for 4 min to slightly freeze the tissue. Two-mm coronal sections from the olfactory bulb to the cerebellum were prepared, stained with $1.5 \%$ TTC (Genetime) at $37{ }^{\circ} \mathrm{C}$ for $30 \mathrm{~min}$, and fixed in $10 \%$ buffered formalin solution.

\section{Transmission electron microscopy}

Seven days after PCI, the peripheral penumbra at $7 \mathrm{~mm}$ posteriorly to the bregma and $3 \mathrm{~mm}$ laterally from the midline on the injury side was removed and immediately cut into $0.5 \mathrm{~cm}^{3}$ cubes at $0{ }^{\circ} \mathrm{C}$, fixed with $4 \%$ paraformaldehyde for $4 \mathrm{~h}$, and washed with PBS. Then, the tissue was fixed with $2 \%$ osmic acid for $2 \mathrm{~h}$, washed with pure water, dehydrated with a mixture of ethanol, propylene oxide, and resin, embedded in pure resin, and ultramicrocut and stained with uranyl acetate and lead citrate $[13,14]$. The sections were observed under an HE-800 transmission electron microscope (Hitachi, Japan).

\section{Western blotting}

The cortex from the injury side was collected at 7 days after injury and homogenized in a lysis buffer (in mM: Tris, 10, pH 7.4; $\mathrm{NaCl}, 150$; EDTA, 1; EGTA, 1; $10 \%$ protease inhibitor, $1 \%$ phosphatase inhibitor), and incubated on ice for $30 \mathrm{~min}$. The protein lysate was then 
centrifuged at $13,500 \mathrm{rpm}$ for $30 \mathrm{~min}$ at $4{ }^{\circ} \mathrm{C}$. The supernatant was aliquoted and stored at

$-80{ }^{\circ} \mathrm{C}$ until its use. The supernatant was measured for its protein concentration using a Bio-Rad DC Protein Assay Kit (Bio-Rad Laboratories, CA, USA). A $40 \mu \mathrm{g}$ aliquot of protein from each sample was subjected to 5-12\% SDS-polyacrylamide gel electrophoresis and transferred onto a PVDF membrane. Each membrane was blocked with 5\% non-fat milk and $2 \%$ bovine serum albumin in Tris-buffered saline containing $0.1 \%$ Tween 20 (TBST) for $1 \mathrm{~h}$ at room temperature and then probed with rabbit anti-p-JNK (Cell Signaling Technology, MA, USA), anti-p-c-JUN (Cell Signaling Technology), p-ATF-2 (Cell Signaling Technology), total-JNK (Cell Signaling Technology) and total-RhoA antibodies at $4{ }^{\circ} \mathrm{C}$ overnight. As a gel loading control, $\beta$-actin was used. After washing, the membranes were incubated for $2 \mathrm{~h}$ with horseradish peroxidase-conjugated goat anti-rabbit antibody (1:2000; DakoCytomation, Denmark). Its immunoreactivity was visualized using the Amersham enhanced chemiluminescence kit (Amersham, Piscataway, NJ, USA). The protein loading was controlled using the goat antibody against $\beta$-actin (C-11; Santa Cruz Biotechnology). The quantification of the results was performed by densitometry, and the results were analyzed as total integrated densitometric values (arbitrary units). The protein GTP-RhoA was pulled down using a RhoA activation assay kit, according to the manufacturer's instruction (Cytoskeleton, Denver, CO, USA) and assayed by Western blotting using an antibody against RhoA (Cytoskeleton). All experiments for Western blotting were performed with 3 animals in each group, and the samples were run on the gels as individual animals.

\section{Data and statistical analysis}

The values are presented as the mean $\pm \mathrm{SD}$. The statistical analyses was performed using Student's t-test for comparisons between two groups or the one-way analysis of variance (ANOVA) followed by post-hoc tests (Student-Neuman-Keuls) for comparisons of 
more than two groups. The data were analyzed statistically with the software SPSS 12.0. The significance level was set at $\mathrm{P}<0.05$.

\section{Results \\ Measurement of brain infarct volume and identification of blood brain barrier integrity}

After TTC staining, the rats in the sham group did not appear to have any infarctions (Fig. 1b). However, the right parietal lobes of the rats $24 \mathrm{~h}$ after PCI presented pale infarctions that were bowl-shaped, with the bottom pointing to the lateral ventricle; these infarctions affected the entire cortex. The total infarct volumes were $297.1 \pm 23.4 \mu 1$ in the PBS group and $285.4 \pm 19.7 \mu 1$ for the $\mathrm{sNgR}-\mathrm{Fc}$ group respectively before the treatment. The locations of the infarctions were stable, and the infarctions showed similar volumes to those in the rats (Fig. 1).

\section{Pathological changes of axons}

The morphology of ischemic penumbra on the injury side was evaluated using TEM at 7 days after PCI. Compared with the normal axons observed in the sham group (Fig. 2a), more serious pathologies were observed in the PCI group (Fig. 2b). For the axons without a medulla sheath, many edemas, dilutions of cytoplasmic matrices, and axonal fusions or dissolutions were found. Occasionally, we observed that oligodendrocytes appeared to "swallow" the axons (Fig. 2b). For axons with a medulla sheath, compared with the sham group, thickening or shrinking was more in the axoplasm of the fibers, and amyloidosis and swollen axons were observed at a higher rate. In addition, the axolemma were found to be separated from the inner layers of the myelin (Fig. 2e). In addition, there were only minor pathological changes, including slight nuclear edemas with complete nucleoli, slightly swollen mitochondria, and slightly widened endoplasmic reticula with complete ribosomes 
and Golgi bodies. In unmyelinated axons, there were some axonal edemas, axonal deformities, and dilutions of cytoplasmic matrices; in addition, there were no axonal fusions or cytophagic effects of oligodendrocytes (Fig. 2c). In myelinated axons, the morphology of axons was almost normal. There was little demyelination and no amyloidosis of the myelin sheath was found (Fig. 2f). Compared with normal synapses (Fig. 2g), the synaptic cleft widened, and there was edema in the PBS group (Fig. 2h). However, no clear edema or widening of the synaptic cleft was observed in the group that received the $\mathrm{sNgR}-\mathrm{Fc}$ treatment (Fig. 2i).

\section{sNgR-Fc inhibited RhoA signal pathway}

The level of GTP-RhoA in the PBS group was significantly higher than that in the sham-operation group $(P<0.05)$. After treatment with $\mathrm{sNgR}-\mathrm{Fc}$, the level of GTP-RhoA was significantly decreased. Moreover, the level of Total-RhoA was not different among the three groups (Fig.3, Table 1). These data indicate that $\mathrm{sNgR-Fc}$ could decrease the activation of RhoA.

\section{sNgR-Fc inhibit the activation of SAPK/JNK signal pathway}

The levels of p-JNK1, 2 and its downstream targets, p-c-JUN and p-ATF-2, in the cortex around the infarcts in the PCI group were significantly higher compared with those in the sham operation group $(P<0.05)$. In contrast, the cortex in the sNgR-Fc-treated group showed, on average, reductions in the levels of p-JNK1, 2, p-c-JUN and p-ATF-2 to their basal levels $(P<0.05)$. The levels of total JNK1, 2 were not different among the three groups $(P>0.05)$. These results demonstrate that the cortical infarction injury activates the SAPK/JNK signal pathway and that treatment with $\mathrm{sNgR}-\mathrm{Fc}$ has the potential to decrease or prevent this activation (Fig.3, Table 1). 


\section{Discussion}

Watson et al reported a stroke model induced by a photochemical method in 1985 [12]. The principle underlying this model was based on a photochemical reaction. Following the injection of a potent photosensitive agent into rats, ischemic lesions were formed by irradiating the left parietal convexities of the exposed skulls under a light with a specific wavelength. Free radicals were released, damaging the endothelium of the cerebral vessels and inducing platelet aggregation. Furthermore, this pathology causes thrombosis in cerebral parenchymal vessels and results in irreversible hypoxic-ischemic brain damage (HIBD). Because of the advantages of a stable location and infarction volume, a low mortality rate, and a good replication rate, the stroke model is widely used in current studies of brain injury. In this study, we successfully induced a cortical ischemic infarction model in rats in which the BBB was also damaged. The primary pathological features of stroke were induced, and the volumes of infarction were consistent. No infarction and no burn were observed in the sham-group, indicating that the light stimulation alone did not induce the infarction and that it acts as a good control.

Delayed neuron death (DND) is an important pathology of cerebral ischemia and cerebral degenerative disease. Cell apoptosis was the primary DND pattern after an acute HIBD, which aggravated the injury of sub-acute or chronic cerebral infarction $[15,16]$. In our study, axonal pathologies were observed via the TEM at 7 days after PCI, including many edemas in the axoplasm of axons that have no medulla sheath, and thickening or shrinkage in the sheaths of the axons that have a medulla sheath. However, these conditions improved after $\mathrm{sNgR}-\mathrm{Fc}$ treatment. The administration of the soluble $\mathrm{NgR} 1$ fusion protein $(\mathrm{sNgR}-\mathrm{Fc})$ effectively blocked the interaction of myelin molecules with $\mathrm{NgR} 1$ and promoted axon sprouting and functional recovery after spinal cord injuries[7-9], or dorsal root rhizotomy[10]. 
A previous study found that Nogo-A is involved in the secondary axonal degeneration of the

[18]. Anti-Nogo-A antibody improved behavioral outcome and corticospinal plasticity but did not decrease the infarct volume after experimental stroke [11]. In this study, $\mathrm{sNgR}-\mathrm{Fc}$ did not cause any difference on infarct volume, but still provided protection of axons as observed in TEM.

Nogo-A, MAG and OMgp were considered to be the inhibitory factors of axonal regeneration in the CNS. NgR1 mediates their inhibitory effect via two co-receptors, $\mathrm{p} 75$ and Lingo-1, and transduces the signals via RhoA and its downstream pathways [19, 20]. In this study, the level of the GTP-RhoA protein in the model group was significantly higher than that of the sham-operation group. With the treatment of sNgR-Fc, the level of the GTP-RhoA protein was significantly decreased, suggesting that $\mathrm{sNgR}-\mathrm{Fc}$ may promote axonal recovery by preventing the activation of RhoA after cerebral infarction.

The stress-activated protein kinase/c-Jun N-terminal kinase (SAPK/JNK) signaling pathway is a powerful signaling pathway under the stresses of ultraviolet light, radiation and inflammation [21-23]. In publications on neuronal apoptosis, some of the proteins in the mitogen-activated protein kinases (MAPK) signaling pathways have been well-studied in recent years. The MAPK signaling pathway is a family of serine/threonine kinases that include three members: the extracellular signal-regulated protein kinases (ERK), JNK and p38 [24]. The JNK/SAPK and p38 are induced by cellular stress and some of the cytokines. The JNK protein can be activated by many stress stimulators, such as lipopolysaccharide (LPS), tumor necrosis factor- a (TNF- a ), interleukin (IL)-1 or ultraviolet light. Activation of the JNK signaling pathway is related to cell apoptosis [24]. Following its activation, JNKs may phosphorylate specific sites of some of the transcription factors, such as ATF-2, SAP-1 
and Elk-1, and increase the expression of genes, subsequently increasing the synthesis of proteins that may participate in the apoptosis pathway and cause cell death [25]. We found high levels of p-JNK, p-c-JUN and p-ATF-2 after stroke injury, indicating that cortical infarction activates the SAPK/JNK signal pathway and leads to the pathology of tissues and cells. The administration of $\mathrm{sNgR}-\mathrm{Fc}$ decreased the activation of those proteins, suggesting that $\mathrm{SNgR}-\mathrm{Fc}$ has the potential to prevent or decrease the activation of the SAPK/JNK signal pathway. We previously identified that sNgR-Fc binds to Nogo66, OMgp, and MAG [9] and inhibited the Nogo66- $\mathrm{NgR}$ interaction [6]. sNgR-Fc may protect axons by inhibiting the interaction of Nogo-A-NgR1 after stroke injury, decreasing the activation of RhoA and JNK. A schematic diagram illustrating the proposed mechanism for $\mathrm{sNgR}-\mathrm{Fc}$ on axons in stroke is shown in Figure 4: In normal conditions, the cortex expresses low levels of Nogo-A and $\mathrm{NgR} 1$. However, cortical infarction under stroke injury increases the expression of Nogo-A and NgR1. Nogo-A activates RhoA and JNK signaling pathways via interacting with NgR1 and then results in pathological changes on axons. sNgR-Fc perturbs the interaction of Nogo-A and $\mathrm{NgR} 1$, decreases the activation of RhoA and JNK signaling pathways and relieving the pathological changes of axons.

RhoA regulates the intracellular microfilament associated with cell proliferation through a series of complex mechanisms [26]. Previous studies have observed that RhoA stimulates Jun expression through the Rho-associated kinase (ROCK), which phosphorylates c-Jun and ATF2 after binding to the c-Jun promoter [27]. In this study, we observed that changes in the expression of p-JNK, p-c-Jun and p-ATF-2 were consistent with changes in the GTP-RhoA level following both the cerebral infarction and the sNgR-Fc treatment. These findings suggest that $\mathrm{sNgR}-\mathrm{Fc}$ can relieve the axonal pathology partially by decreasing the activation of the SAPK/JNK signal pathways. 
In summary, pathological changes in axons were induced by the cerebral hypoxia-ischemia for an extended period after the cortical infarction. This phenomenon may be associated with the activation of RhoA/ROCK/JNK/c-Jun signaling pathways. We determined that an $\mathrm{NgR} 1$ antagonist, $\mathrm{sNgR}-\mathrm{Fc}$, alleviated axonal pathology changes and prevented the activation of RhoA/ROCK/JNK/c-Jun signaling pathways. Further studies should be performed before this treatment is used in a clinical study.

\section{Acknowledgements}

This study was supported by funding from the NSFC (81272062, 81071030), Science and Technology Foundation of Guangdong Province, China (2012B031800286 , 2010B031600089) and the Fundamental Research Funds for the Central Universities (09ykpy31). The funders had no role in the study design, data collection, analysis, decision to publish or the preparation of the manuscript. Biogen Idec, Inc. provided the sNgR-Fc in the study.

\section{Disclosure of potential conflicts of interest}

The authors indicate no potential conflicts of interest. 


\section{References}

1. Bühnemann C, Scholz A, Bernreuther C, Malik CY, Braun H, Schachner M et al (2006)

Neuronal differentiation of transplanted embryonic stem cell-derived precursors in stroke lesions of adult rats. Brain 129:3238-3248

2. Chen MS, Huber AB, van der Haar ME, Frank M, Schnell L, Spillmann AA et al (2000) Nogo-A is a myelin-associated neurite outgrowth inhibitor and an antigen for monoclonal antibody IN-1. Nature 403:434-439

3. Domeniconi M, Cao Z, Spencer T, Sivasankaran R, Wang K, Nikulina E et al (2002) Myelin-associated glycoprotein interacts with the Nogo66 receptor to inhibit neurite outgrowth. Neuron 35:283-290

4. Wang KC, Koprivica V, Kim JA, Sivasankaran R, Guo Y, Neve RL et al (2002) Oligodendrocyte-myelin glycoprotein is a Nogo receptor ligand that inhibits neurite outgrowth. Nature 417:941-944

5. GrandPre T, Li S, Strittmatter SM (2002) Nogo-66 receptor antagonist peptide promotes axonal regeneration. Nature 417:547-551

6. Harvey PA, Lee DH, Qian F, Weinreb PH, Frank E (2009) Blockade of Nogo receptor ligands promotes functional regeneration of sensory axons after dorsal root crush. $\mathrm{J}$ Neurosci 29:6285-6295

7. Ji B, Li M, Budel S, Pepinsky RB, Walus L, Engber TM et al (2005) Effect of combined treatment with methylprednisolone and soluble Nogo-66 receptor after rat spinal cord injury. Eur J Neurosci 22:587-594

8. Lee JK, Kim JE, Sivula M, Strittmatter SM (2004) Nogo receptor antagonism promotes stroke recovery by enhancing axonal plasticity. J Neurosci 24:6209-6217

9. Li S, Liu BP, Budel S, Li M, Ji B, Walus L et al (2004) Blockade of Nogo-66, 
myelin-associated glycoprotein, and oligodendrocyte myelin glycoprotein by soluble Nogo-66 receptor promotes axonal sprouting and recovery after spinal injury. J Neurosci 24:10511-10520

10. MacDermid VE, McPhail LT, Tsang B, Rosenthal A, Davies A, Ramer MS (2004) A soluble Nogo receptor differentially affects plasticity of spinally projecting axons. Eur J Neurosci 20:2567-2579

11. Wiessner C, Bareyre FM, Allegrini PR, Mir AK, Frentzel S, Zurini M, et al (2003) Anti-Nogo-A antibody infusion 24 hours after experimental stroke improved behavioral outcome and corticospinal plasticity in normotensive and spontaneously hypertensive rats. J Cereb Blood Flow Metab. 23:154-65.

12. Watson BD, Dietrich WD, Busto R, Wachtel MS, Ginsberg MD (1985) Induction of reproducible brain infarction by photochemically initiated thrombosis. Ann Neurol $17: 497-504$

13. Gao M, Zhu SY, Tan CB, Xu B, Zhang WC, Du GH (2010) Pinocembrin protects the neurovascular unit by reducing inflammation and extracellular proteolysis in MCAO rats. J Asian Nat Prod Res 12:407-418

14. Zheng YQ, Liu JX, Wang JN, Xu L (2007) Effects of crocin on reperfusion-induced oxidative/nitrative injury to cerebral microvessels after global cerebral ischemia. Brain Res 1138:86-94

15. Culmsee C, Plesnila N (2006) Targeting Bid to prevent programmed cell death in neurons. Biochem Soc Trans 34:1334-1340

16. Plesnila N, Zhu C, Culmsee C, Gröger M, Moskowitz MA, Blomgren K (2004) Nuclear translocation of apoptosis-inducing factor after focal cerebral ischemia. J Cereb Blood Flow Metab 24:458-466 
17. Wang F, Liang Z, Hou Q, Xing S, Ling L, He M et al (2007) Nogo-A is involved in secondary axonal degeneration of thalamus in hypertensive rats with focal cortical infarction. Neurosci Lett 417:255-260

18. Cheatwood JL, Emerick AJ, Schwab ME, Kartje GL (2008) Nogo-A expression after focal ischemic stroke in the adult rat. Stroke 39:2091-2098

19. Kubo T, Hata K, Yamaguchi A, Yamashita T (2007) Rho-ROCK inhibitors as emerging strategies to promote nerve regeneration. Curr Pharm Des 13:2493-2499

20. Kubo T, Yamashita T (2007) Rho-ROCK inhibitors for the treatment of CNS injury. Recent Patents CNS Drug Discov 2:173-179

21. Schwab TS, Madison BB, Grauman AR, Feldman EL (2005) Insulin-like growth factor-I induces the phosphorylation and nuclear exclusion of forkhead transcription factors in human neuroblastoma cells. Apoptosis 10:831-840

22. Zhang HM, Yuan J, Cheung P, Luo H, Yanagawa B, Chau D et al (2003) Overexpression of interferon-gamma-inducible GTPase inhibits coxsackievirus B3-induced apoptosis through the activation of the phosphatidylinositol 3-kinase/Akt pathway and inhibition of viral replication. J Biol Chem 278:33011-33019

23. Koh SH, Lee YB, Kim KS, Kim HJ, Kim M, Lee YJ et al (2005) Role of GSK-3beta activity in motor neuronal cell death induced by G93A or A4V mutant hSOD1 gene. Eur J Neurosci 22:301-309

24. Yasuda S, Sugiura H, Tanaka H, Takigami S, Yamagata K (2011) p38 MAP kinase inhibitors as potential therapeutic drugs for neural diseases. Cent Nerv Syst Agents Med Chem. 11:45-59.

25. Humar M, Loop T, Schmidt R, Hoetzel A, Roesslein M, Andriopoulos N et al (2007) The mitogen-activated protein kinase p38 regulates activator protein 1 by direct 
phosphorylation of c-Jun. Int J Biochem Cell Biol 39:2278-2288

26. Marinissen MJ, Chiariello M, Tanos T, Bernard O, Narumiya S, Gutkind JS (2004) The small GTP-binding protein RhoA regulates c-jun by a ROCK-JNK signaling axis. Mol Cell 14:29-41

27. Karin M, Liu Z, Zandi E (1997) AP-1 function and regulation. Curr Opin Cell Biol 9:240-246 


\section{Figure Legends}

Figure 1. The morphology and characteristics of the rat brain after a stroke induced by photothrombotic cortical injury. (a) Representative photographs of the coronal brain sections stained with 2,3,5-triphenyltetrazolium chloride in rats, (b) sham-operated rats, (c) and photothrombotic cortical injury (PCI) rats. White indicates the infarct area (arrow).

\section{Figure 2. The protective effect of $\mathrm{SNgR-Fc}$ on axon neurons under transmission electron} microscope after stroke injury. Ultrastructural appearances of morphology of axons in sham-operated, PBS and sNgR-Fc groups: (a) Normal unmyelinated axons in sham-operated group; (b) Extensive edema, axon deformity, dilution of cytoplasmic matrices and axonal fusion in stroke model; (c) Slight edema and dilution of cytoplasmic matrices with the treatment of sNgR-Fc in stroke model; (d) Normal myelinated axons in sham-operated group; (e) Thickening, shrinking or amyloidosis was more in stroke model; (f) Little demyelination and no amyloidosis of the myelin sheath were found with the treatment of $\mathrm{sNgR}-\mathrm{Fc}$ in stroke model; (g) Normal synapses in the sham-operated group; (h) Widened and swollen synaptic cleft in stroke model; (i) Approximately normal synapses with the treatment of $\mathrm{sNgR}-\mathrm{Fc}$ in stroke model. Arrows show the changes in axons.

Figure 3. The RhoA, SAPK/JNK signaling pathways after stroke injury and with the treatment of sNgR-Fc under Western blotting. The levels of p-JNK, p-c-JUN, p-ATF-2 and GTP-RhoA increased after stroke injury. Treatment with sNgR-Fc decreased the levels of p-JNK, p-c-JUN, p-ATF-2 and GTP-RhoA to normal levels.

Figure 4. The diagram of the signaling pathways involved in the sNgR-Fc on axons after stroke injury. In the normal condition, there is low level of Nogo-A and NgR1 in the cortex. However, the expression of Nogo-A and NgR1 is increased under stroke injury. The increased Nogo-A binds with NgR1 to activate the downstream pathways of RhoA and JNK, and then results in axonal pathology. The treatment of $\mathrm{sNgR}-\mathrm{Fc}$ inhibits the interaction of Nogo-A and $\mathrm{NgR} 1$, decreases the activation of RhoA and JNK signaling pathways and then relieves axonal pathology. 

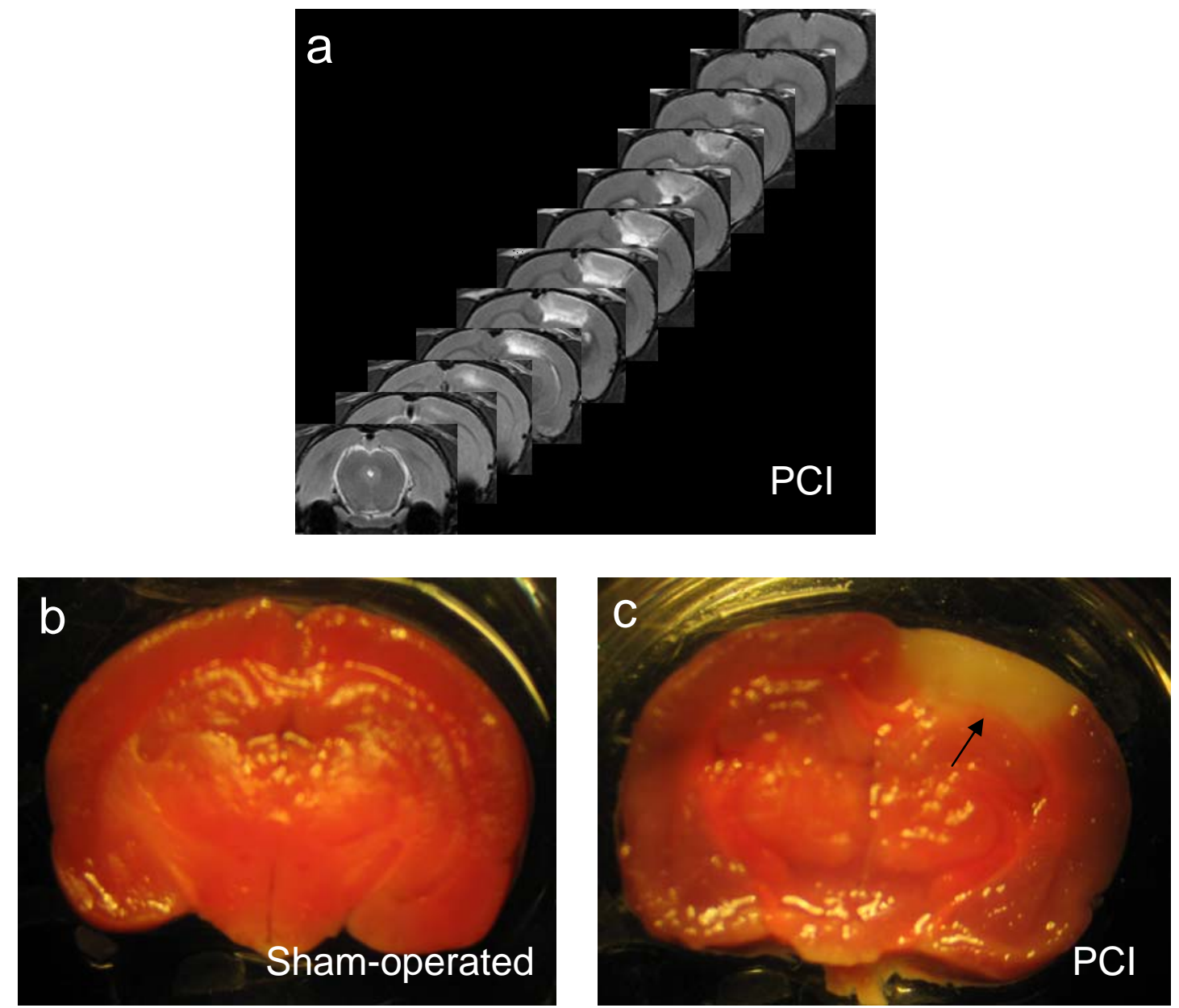

Figure 1 


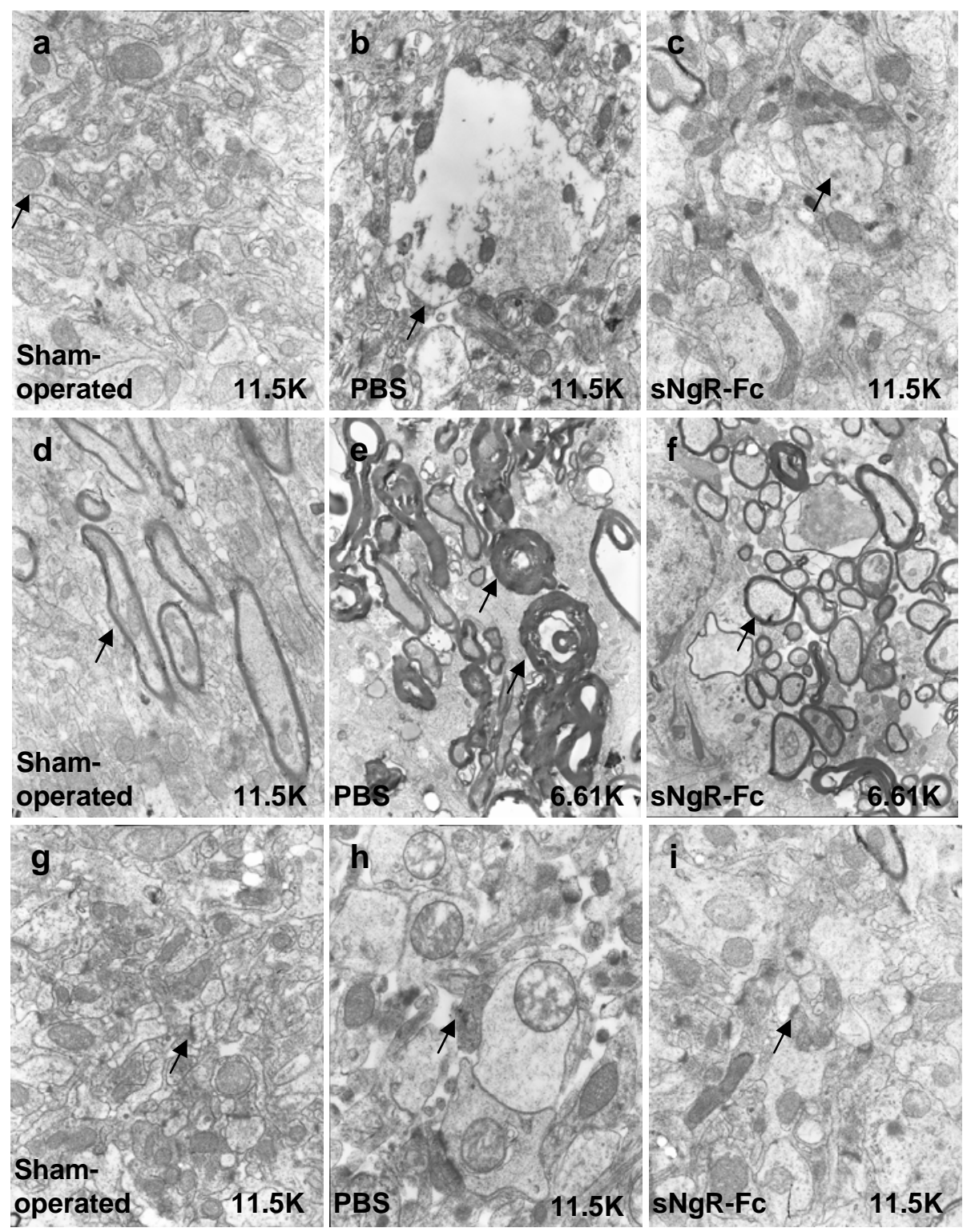

Figure 2 


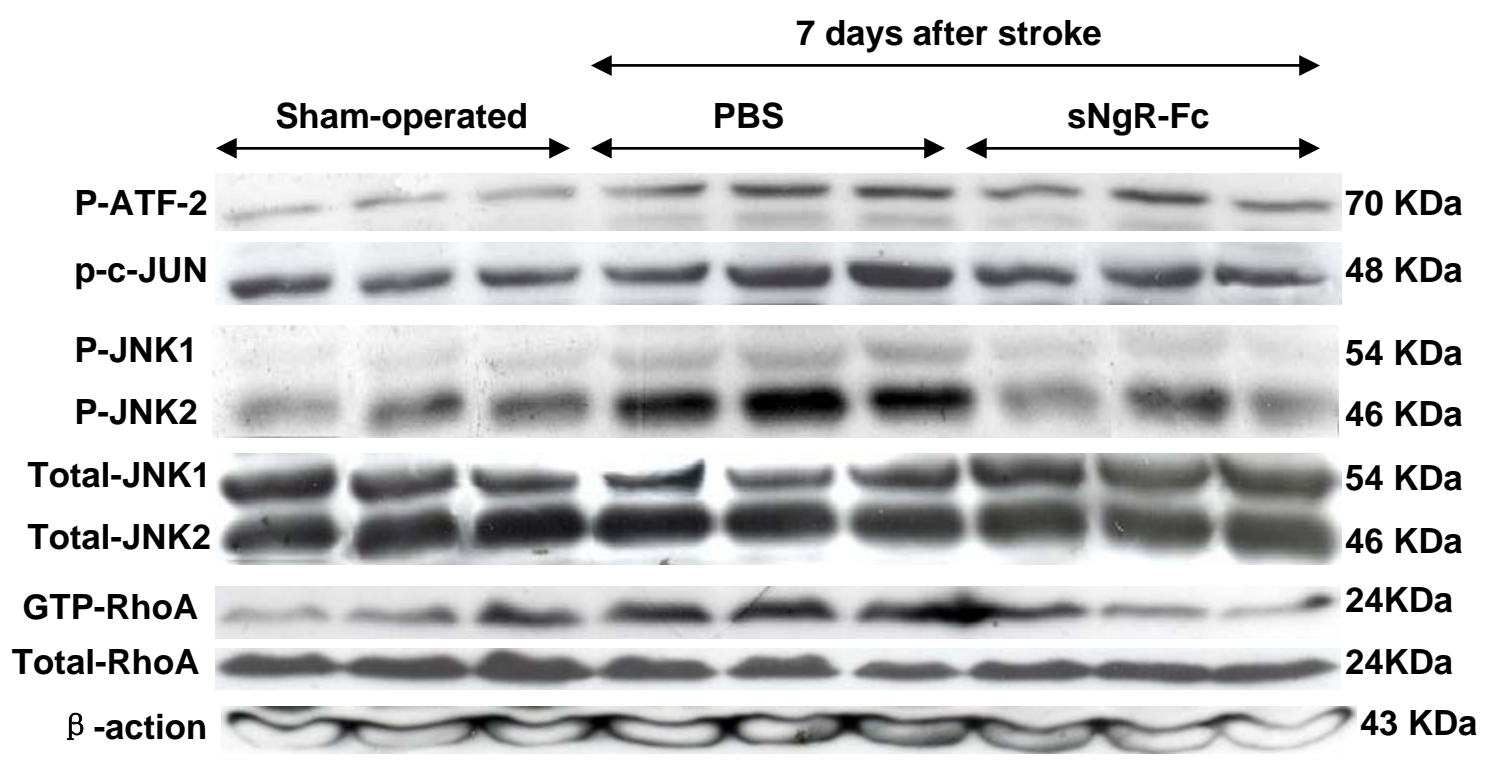

Figure 3 


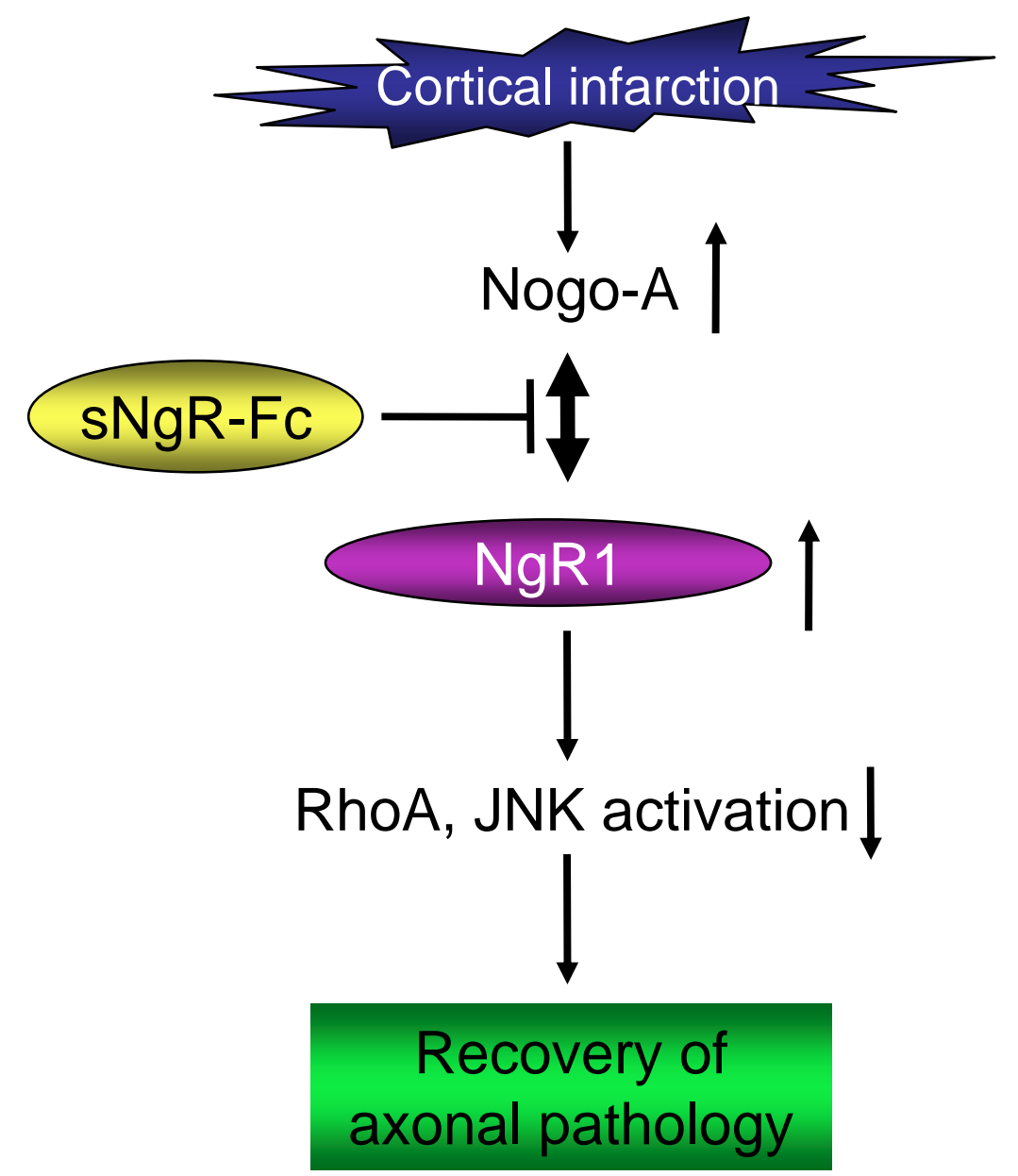

Figure 4 
Table 1 The density of the key proteins of RhoA and SAPK/JNK signal pathway

\begin{tabular}{|c|c|c|c|}
\hline & Sham-operated & PBS & sNgR_Fc \\
\hline GTP-RhoA & $1.0 \pm 0.14$ & $1.73 \pm 0.16^{\Delta}$ & $1.10 \pm 0.13^{\boldsymbol{\square}}$ \\
\hline Total-RhoA & $1.0 \pm 0.09$ & $0.97 \pm 0.11$ & $0.98 \pm 0.10$ \\
\hline p-ATF-2 & $1.0 \pm 0.12$ & $2.19 \pm 0.24^{\Delta}$ & $1.53 \pm 0.22^{\Delta \square}$ \\
\hline p-c-JUN & $1.0 \pm 0.062$ & $1.39 \pm 0.139^{\wedge}$ & $1.12 \pm 0.058^{\boldsymbol{\square}}$ \\
\hline $\mathrm{p}-\mathrm{JNK} 1$ & $1.0 \pm 0.29$ & $2.24 \pm 0.27^{\boldsymbol{\Delta}}$ & $1.30 \pm 0.31^{\wedge !}$ \\
\hline p-JNK2 & $1.0 \pm 0.14$ & $1.73 \pm 0.12^{\Delta}$ & $1.02 \pm 0.15^{\boldsymbol{\Delta}}$ \\
\hline Total-JNK1 & $1.0 \pm 0.08$ & $1.01 \pm 0.09$ & $1.01 \pm 0.08$ \\
\hline Total-JNK2 & $1 \pm 0.09$ & $0.99 \pm 0.11$ & $0.98 \pm 0.12$ \\
\hline
\end{tabular}

${ }^{\Delta} \mathrm{P}<0.05$ vs Sham-operated group; ${ }^{-\mathrm{P}}<0.05$ vs $\mathrm{PBS}$ group, Mean $\pm \mathrm{SD}, \mathrm{n}=3$ ) 